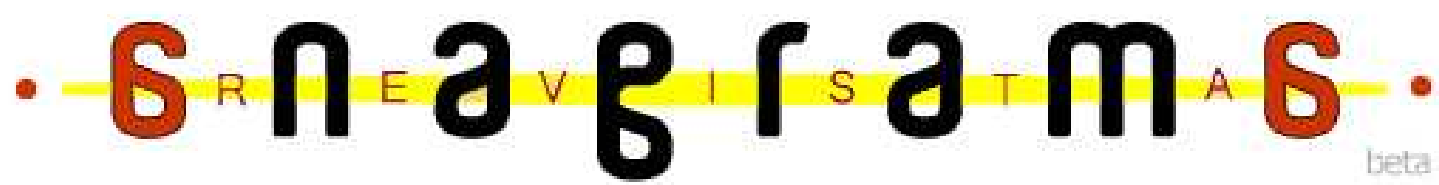

\section{A Digitalização e o Diálogo do Audiouisual}

\section{Ewerton Luis Faverzani Figueiredo ${ }^{7}$}

\section{Resumo}

O impacto digital dos medias constitui uma fase de crise na qual gera um determinismo tecnológico sem volta. Somos guiados por forças fascinantes das novas tecnologias que nos manipulam e nos desterritorializam, submetendo-nos para uma não-presença em que o tempo se torna imensurável. Diante dessa nova situação de comunicação, procura-se refletir, à luz da semiótica do audiovisual acerca das contribuições de Lévy, Parente, Flusser, Pignatari, Stiegler, Felinto e Teixeira para os estudos de comunicação, ao propor que as imagens pós-históricas possuem uma relação de apropriação das imagens préhistóricas como mecanismos de atualização virtual. São imagens técnicas que, através dos textos ancestrais, virtualizaram-se em novos conceitos de mundo onde as fórmulas e cálculos matemáticos imperam. As imagens técnicas excluíram de certo modo os poderes da palavra e, hoje, tendemos a ser cada vez mais programados por elas. Deste modo, este estudo tem por objetivo contribuir para um diálogo filosófico sobre o aparelho em função do qual vive a atualidade, tomando por pretexto a análise da TV Digital.

Palauras-chaue: Novas tecnologias; Imagens técnicas; Teoria da comunicação.

\section{Introdução}

O momento atual, de convergência midiática, ou a migração digital dos medias, passa por uma fase de transição em que o processo de comunicação televisual que conhecemos quando inserido nos sistemas totalmente digitalizados, seja na transmissão em TV aberta, cinema de modo que a migração da televisão analógica para a digital apresenta a atual constituição de uma nova mídia. Este impacto digital constitui uma fase de crise, na qual gera um determinismo tecnológico sem volta. Somos guiados por forças fascinantes

\footnotetext{
${ }^{1}$ Graduado em Comunicação Social - Relações Públicas pela UFSM. E-mail: ewertonfaverzani@gmail.com.
} 
das novas tecnologias que nos manipulam e nos desterritorializam, submetendo-nos para uma não-presença em que o tempo se torna imensurável.

Diante dessa nova situação de comunicação, procura-se refletir, à luz da semiótica do audiovisual, acerca das contribuições de Lévy, Parente, Flusser, Pignatari, Stiegler, Felinto e Teixeira para os estudos de comunicação, ao propor que as imagens pós-históricas possuem uma relação de apropriação das imagens pré-históricas como mecanismos de atualização virtual. São imagens técnicas que, através dos textos ancestrais, virtualizaramse em novos conceitos de mundo onde as fórmulas e cálculos matemáticos imperam. As imagens técnicas excluíram de certo modo os poderes da palavra e hoje tendemos a ser cada vez mais programados por elas. Deste modo este estudo tem por objetivo contribuir para um diálogo filosófico sobre o aparelho em função do qual vive a atualidade, tomando por pretexto a análise da TV Digital.

Para a semiótica, interessa o sentido, o conteúdo, mas não há conteúdo sem expressão. Avaliamos ser relevante considerar a problemática da enunciação na televisão nessa nova plataforma, pelo fato de os textos midiáticos constituírem semióticas, que, inseridas em determinados contextos socioculturais, detêm certo modo de presença e determinam formas de interação, forjando uma práxis enunciativa. Ao converter a expressão em conteúdo, no processo de semiose, não podemos deixar de considerar que o plano de conteúdo é construído sempre pela relação entre as unidades significantes, sejam elas manifestadas por signos isolados ou por conceitos de imagens audiovisuais no exame das possibilidades expressivas específicas da nova mídia.

Para desempenhar tal tarefa, um longo caminho de desenvolvimento teórico terá ainda que ser percorrido. O primeiro passo talvez seja investigar o instrumento teóricoconceitual referente ao conceito dos autores em relação ao audiovisual, objetivando refletir sobre os procedimentos de abordagem do conceito televisivo no contexto digital.

\section{A TU Digital: do possíuel ao real, do virtual ao atual}

A partir do final do século XX e início do século XXI, profundas transformações envolvendo mudanças nas tecnologias de transmissão de informações tendem a criar um novo sentido de estar no mundo. Essas mudanças decorrem da troca gradual dos padrões de transmissão analógicos pelos digitais.

Com isso, a TV analógica será substituída pela digital que possui recursos tecnológicos provenientes em boa parte das redes virtuais de computadores. O analógico é 
um possível já constituído, onde sua natureza não modifica o seu estado real. Como real, o analógico torna-se um possível, pelo fato de criar no espectador sensações bastante próximas do real, embora passíveis de contextos estéticos já constituídos como um desenho animado dentro da grade de programação televisiva infantil, por exemplo. Neste caminho de pensamento, a TV analógica executa programas puramente lógicos, sem a interferência humana para sua execução, apenas os dotando como criadores de sistemas técnicos e produtores potenciais desses programas. Isto tende a aproximar os seres humanos dos sistemas informáticos (sistemas de informações programadas como o envio de um e-mail para um programa de televisão que dependa da participação do telespectador, por exemplo) que se virtualizam num contexto virtual/atual (LÈVY, 1996).

Deste modo a TV digital dotada de interatividade através de modificações em seu software e hardware proporciona uma ruptura nova, atualizada do analógico, em que promove maior resolução de imagem e qualidade de som, assim como opções de canais, interatividade instantânea na própria tela on line entre o telespectador e os programas exibidos. Que tende a transcender para um novo real atualizado a partir da virtualização dos espaços que decompõem e hibridiza desterritorializando fronteiras, em que o possível vem a ser um novo conceito que difere do anterior, o analógico. A TV digital colabora para um fator de "não-presença" do telespectador, como o que acontece com o ambiente da internet, por serem produtos matemáticos de mesma origem (códigos binários e pixels de resolução). E é justamente aí que o digital tende a ser um corpo em que a alma do telespectador possa, enfim, desterritorializar-se (LÈVY, 1996:21). Passa a ser como um médium que inserido no conteúdo da informação virtual, torna-se "extra-corpo", "nãopresente" e se desintegra no ciberespaço digital. Isto já ocorre com a internet, com os internautas e deve seguir também para os usuários de TV digital.

Deste modo, a TV digital tende a estabelecer-se como um virtual que segundo Parente não remete a um para além do real, mas a uma vontade (ou não) de constituição do real enquanto novo (PARENTE, 1999:14). O analógico como real, como possível fantasmático, busca na sua essência a atividade atualizável de uma evolução dos sistemas de informação para um novo código (binário, 0 e 1), rápido e atual: o virtual, mas tátil, mais próximo da realidade, mais comestível, mais próximo ao toque que tende a ser a TV digital assim como outros meios digitais alternativos. Esta circunstância cria condições de modelagem do sujeito e do mundo, atualizando-o. Por ser a tecnologia digital legada por moldes numéricos, Parente percebe serem estes os responsáveis pelas imagens de síntese, 
imagem e realidade virtuais, autorreferentes. Se alguma coisa pré-existe à imagem de síntese, é o programa, isto é, os números (algoritmos) em que a imagem não mais representa o real, mas o simula (PARENTE, 1999:15).

\section{Imagens técnicas e o problema do aparelho}

Com o surgimento da televisão analógica, modificaram-se as técnicas de imagem antes verificadas como possibilidades reais pré-históricas advindas das pinturas, esculturas e da literatura escrita. Com o aparecimento da fotografia, percebeu-se que uma obra de arte poderia ser reproduzida inúmeras vezes. A fotografia da Mona Lisa, por exemplo, remetia a uma imagem reprodutível pela câmera fotográfica da obra de fato. Um real dentro de um possível de possibilidades de reprodução maquinário. A máquina fotográfica foi a base para o surgimento do movimento em que a realidade do mundo no qual nos inserimos poderia ser reproduzida, reinventada. Dar movimento às imagens estáticas tornou-se uma forma de quebrar com o conceito de máquina estática e vencê-la. A partir dos filmes cinematográficos, verifica-se uma série de imagens em movimento, onde são idênticas as que fisicamente compõem o filme, aos fotogramas que compõem sua fita.

Para Flusser, o teatro representa o mundo das coisas por meio das próprias coisas, e o filme representa o mundo das coisas por meio da projeção das coisas, a leitura de filmes se passa no plano da tela, como ocorre nas pinturas (embora se trate da leitura de imagens falantes) (FLUSSER, 2007:107). O filme dotou as fotografias não de apenas movimentos. Se bem que os primeiros filmes cinematográficos não se constituíam de falas orais, mas de mímicas, ou mesmo texto inseridos entre uma cena e outra, dando a ideia de expressar a fala através de textos escritos. Com o surgimento dos filmes falados, os movimentos de ação humana também se tornaram movimentos de fala, com sons e ritmos que criaram uma atmosfera mágica em que a plateia era aderida, completando o contexto da realidade cotidiana. Isto despertou maior interesse das pessoas e as salas de cinema ficaram cada vez mais lotadas, a ponto de construírem salas que comportassem maior número de pessoas.

Com o advento da televisão, perde-se uma boa fatia do público das salas de cinema. Pois como produto de novidade, está impregnado de fascínio por possuir características semelhantes à tela de cinema, mesmo em padrões menores, com possibilidade de invadir as casas das famílias e dali tornar-se parte delas, unindo-as em torno da mesma. Assim, as leituras de filmes e de certa forma de televisão, por serem aparelhos que reproduzem movimentos e falas, embora difiram na ordem da técnica de produção, segundo Flusser, 
são parecidas com a leitura escrita, por seguirem um texto que é da ordem da superfície linear, da natureza (FLUSSER, 2007:110). Isto porque, tanto nos textos como nos filmes, percebemos a mensagem somente no final de nossa leitura. Mas diferem na razão de que nos filmes, em oposição ao que ocorre nos textos escritos e pinturas, percebemos, primeiro, cada cena para, posteriormente, analisá-la. Os filmes, a televisão são componentes midiáticos da ordem da superfície, ou seja, são linhas de textos inseridas na formação de imagens técnicas que remetem a um conceito pós-histórico, o da atualização de imagens. O que não acontece nos textos escritos, por somente desempenharem aquilo que se chama de pensamento consciente que se perde na vida conforme novos textos são assimilados no pensamento. Eles se atualizam numa constante de esquecimento dos antigos em função de novos, seguindo uma autorreferenciação. A televisão é da ordem do subconsciente, por já possuir um formato elaborado, de fácil manipulação do receptor.

Assim, para Flusser, a história de um filme será algo parcialmente manipulável pelo leitor até que se torne relativamente reversível. Deste modo, há um novo sentido que envolve esses dois paradigmas em que a "liberdade histórica" como expressão é entendida para quem pensa em linhas escritas a possibilidade de atuar na história dentro da história. E para os que, em filmes, como possibilidade de atuar sobre a história para fora dela. Por isso, aqueles que pensam em linhas escritas (as elites), permanecem dentro da história, e aqueles que pensam em filmes, olham para ela de fora (as massas) (FLUSSER, 2007:115). Portanto, tanto os filmes, como até mesmo a televisão, são percebidas como imagens fotográficas em pleno movimento que falam, contam uma história para fora dela.

A televisão analógica, dando lugar a um novo modo de reprodução em qualidade de transmissão, som e imagem, trouxe a possibilidade do virtual como superfície que, comparando com o que Flusser diz a respeito dos filmes, em termos virtuais como superfícies em que para o ouvido são tidos como espaciais, remetendo para uma mescla de sons atualizados por um software determinado que tenta jogar a favor do aparelho, a partir do que já está foi criado em hardware como a TV digital proporciona, uma imagem igual à tela de cinema com sons espaciais alocados ao Home Theater. Um DJ, ou VJ, por exemplo, joga contra o aparelho, a ponto de vencê-lo e criar um novo conceito sonoro.

Para Flusser, nadamos no oceano de sons, e ele nos penetra enquanto nos confrontamos com o mundo das imagens, esse mundo que nos circunda e acaba por nos mediunizar, desterritorializando-nos (FLUSSER, 2007:109). Somos, para as mídias digitais interativas, como a TV digital, advinda da internet, a sincronização híbrida de sons e 
códigos binários que misturam sons espaciais, imagens táteis e interatividade, absorvendo o corpo humano aos aparelhos digitais de modo a nos robotizar. Percebe-se aí uma utopia à primeira vista, a da mutação do homem em ciborgue através do seu corpo, meditando por intermédio dos aparelhos virtuais. Nisto, seu corpo estático, inerte, liberta sua alma no ambiente virtual no qual participa transportando-o pelo mundo desterritorializado em fração de segundos, como se médium fosse. A ideia de segundos é vaga e está contida no aparelho virtual como instantâneo. Fora dele, a realidade é de que justamente não se passaram segundos, mas um dia inteiro de 24 horas.

Flusser também indica que as imagens não necessitam mais se adequarem a experiência imediata do mundo, e essa experiência é abandonada, ou seja, o mundo da ficção-em-superfície, o mundo das massas, subjetivo, está marcado cada vez mais por seu caráter fictício (FLUSSER, 2007:116). A TV digital, como nos filmes atuais, são obras pós-modernas, produtos do aparelho, conceitos de mundo, produtos tecnológicos. Nos bastidores das imagens que nos programam, verifica-se uma teoria científica como não se pode averiguar nas imagens pré-modernas como a pintura, a escultura e mesmo os textos escritos (FLUSSER, 2007:129). Este autor diz ainda que um programa de TV não é uma cena de uma circunstância, mas um "modelo", a saber, uma imagem de um conceito de uma cena (FLUSSER, 2007:136). Por exemplo, uma sala de estar como imagem na tela da TV digital não é uma sala de estar, mas um conceito de sala de estar. Ela nos engana por falsear um real não possível, mas um conceito de mundo. A sala de estar é uma imagem técnica, um conceito de mundo realizável no software como programação. No qual a TV digital joga em favor do aparelho, ou seja, de sua tecnologia constituída, de seu sistema de hardware já elaborado. Dizendo assim, a sala de estar como conceito é o resultado de teorias científicas que necessitam de textos para funcionar. São tecno-imagens que criam um mundo de mitos e magia. As imagens técnicas são magias pós-históricas que se ilustram a partir de um texto e criam, a partir dele, novos conceitos para coisas. A magia da TV digital, assim como a dos filmes atuais, reproduz conceitos de um mundo pós-histórico, com o intuito de manipular as pessoas, as massas. O aparelho digital, futurológico, consome-nos e, de certo modo, acaba por determinar nossas vontades e modos de pensar o mundo. Na maioria das vezes, somos atraídos como um ímã para este determinismo que nos robotiza, ao mesmo tempo em que nos insere num jogo de sedução, usando a máscara da plenitude de tempos, como se tudo coubesse numa caixa preta, devorando o tempo 
linear, congelando-o em imagens. Essas imagens fluem dessa caixa como um pretexto para os programas, visto da situação atual que a história se encontra.

\section{Os signos estão crescendo: a TU digital e os processos de significação}

Através do pensamento humano, as possibilidades reais de criação e reprodução do mundo real do qual participamos segue um contexto evolutivo em que as imagens se apropriam cada vez mais de nossas vidas como conceitos de um mundo de signos e códigos realizáveis no âmbito dos sistemas de informação virtuais. Essa evolução só se completa a partir do momento em que suas imagens mentais transcendem espaços reais, na possibilidade de trazer para si um possível como contributo do que se pode ser inventado. Daí, parte-se de suas contribuições mentais como vetores de condições de criação de imagens-objetos que perduram na história no nível de acontecimentos registrados das ações mentais realizantes que rompem o tradicional, superando a própria criação da imagem-objeto existente. Ou seja, tanto a imagem transcendental como a imagem-objeto seguem uma oposição de confronto como forma de neutralizar a diferença existente entre elas (STIEGLER, 1998).

A imagem-objeto, como história, começa com o surgimento da imagem analógica (fotografia analógica) datado do século XIX. A partir da fotografia, e da inclusão nesta do movimento, surge o cinema que é a sequência do movimento de inúmeras fotografias dotando a elas um aspecto de ação, de mobilidade. Porém, somente no final do século XX e início do século XXI que a imagem digital ou de síntese surge. A partir daí, o analógico fílmico se converte em pixels de resolução (matemáticos, binários), desenvolvendo uma suspensão que supera o que até a pouco parecia normal, adaptável, analógico. Nas imagens digitais, mundos virtuais, clones de seres humanos, inteligência artificial, vida e morte artificiais são atualizações que se inserem no domínio das imagens animadas (filmes) (STIEGLER, 1998:182). Surgem como crenças em que sons espaciais e imagens de superfície transformam nossa percepção de mundo, no que Tomás, identifica como por intermédio de próteses de percepção. Nelas, as condições nas quais se constituem nossas crenças ingressaram numa fase de intensa evolução. E a tecnologia digital vem a ser um momento decisivo dessas próteses (STIEGLER, 1998:184). Das imagens digitais, a manipulação se torna uma possibilidade infinita, na qual reduz a impressão que se tem da imagem digital como distinção entre o que é verdadeiro e o que não é. 
Deste modo, verifica-se que a imagem em geral é inexistente no momento em que a imagem mental é inserida em uma história como imagem-objeto também, uma vez que pode ser criada a partir de uma técnica dotando-a de um significante que defina as inúmeras faces de um signo linguístico. Tanto que para Peirce,

\footnotetext{
O signo ou representamem, num contexto de categorias cenoptagóricas é um primeiro que está em única relação com um segundo, chamado seu objeto, de forma a ser capaz de determinar que um terceiro, denominado seu interpretante, assuma a mesma relação triádica (com o objeto) que ele, signo, mantém em relação ao mesmo objeto (PIGNATARI, 2004:49).
}

Em consonância a isso, as imagens digitais são ícones que dotam conceitos de mundo a uma qualidade primeira, através de seus códigos binários ( 0 e 1) que são definidos como signos dentro de um possível de reprodutibilidade fantasmática. Num segundo momento, o da secundidade, em que a imagem técnica de um programa fílmico digital é percebida através da circunstância que ele remete a uma distração de algo inusitado que ocorre no filme, extraindo-nos da inércia e nos remetendo a um estado de análise de um signo, no qual se refere ao objeto designado em virtude de ser realmente afetado por ele. É, num terceiro momento, a terceiridade, na qual, a partir da observação do índice, em que desperta minha atenção, no que passo a perceber o signo ao referir-se ao objeto de forma que parta para uma associação geral de ideias a partir do índice, remetendo-me a convenções mais amplas.

\section{Deuires da TU digital}

A partir dos textos de Francisco Teixeira, e sua análise do filme Limite de Mário Peixoto, pode-se fazer uma observação nas transformações técnicas de imagem advindas da TV digital através das contribuições de Erick Felinto no livro "A rebelião das máquinas, ensaios sobre a imaginação da cibercultura".

O Limite de um filme para além do limite, a finitude, um deslimite, um intangível que já não é mais da ordem de uma especialidade a vislumbrar, de um interior ou exterior a traçar, mas de um fora-dentro a sensoriar, fora-dentro que as reiterações da forma-barco e da forma-ilha não param de lançar (TEIXEIRA, 2003:17).

A esse respeito, o Limite, filme de Mário Peixoto filmado entre maio de 1930 e janeiro de 1931, instaura um devir-espaço-temporal da obra do que viria a se consolidar nos dias de hoje, em que as imagens digitais nos alucinam e, ao mesmo tempo, atraem-nos, 
fascinam-nos, por serem imagens textuais que remetem para um fora de mundo. Em Limite, verifica-se essa aproximação, mesmo por ter sido produzido num a época em que não se podia imaginar um futuro de imagens digitais que remetem para uma desterritorialização do corpo humano enquanto possibilidade virtual.

Mesmo assim, em Limite, a atualização surge como única técnica do devir digital de hoje, como a questão do sentido de "não-tempo". Em que o filme recupera sua restauração indo alocar no campo da virtualidade reprodutível que antecede, atualiza e subtrai o filme original. O que segundo Monta,

Há no filme "um tema geral", a finitude com "sede de infinito" frente ao cronológico; há "uma situação", a do barco náufrago com seus três passageiros inertes, há "três histórias", a das vidas desses passageiros que se encontram no barco (TEIXEIRA, 2003:26).

O filme foi remontado. O original foi virtualizado, atualizado para o digital. Houve uma mudança de cenas, de modo a dá-lo mais qualidade. Essa nova atualização seguiu um devir que remete para o contexto do filme de intensidade, de múltiplas intensidades, sempre a nos lançar para fora de alguma história como ocorre com o próprio filme, do original para o momento digital. Um filme que perde seu corpo, mas seu espírito vaga nos espaço, no tempo, e emerge num novo corpo, num formato digital. Assim dizendo segundo Otávio de Faria

O Limite, mesmo quando narra, o que narra não estados de momento, são estados de espírito, são situações pretextos que fazem reverberar acordes, rimas, ritmos. Ora, ao destacar estados de espírito como o que constitui limite, para além de um contar história característica de uma arte da representação (TEIXEIRA, 2003:27).

O filme de Mário Peixoto como arte de representação pode ser comparado às representações que Felinto insiste em comentar a respeito das novas tecnologias de que dispomos atualmente. Sendo elas uma absorção de antigos mitos, de representações arcaicas e anseios primeiros. Associados ao novo, como absoluto, em que essas fantasias ancestrais funcionam como bases que alimentam e ampliam o poder e o fascínio pelas novas tecnologias sem limites (FELINTO, 2006:55).

Como no filme Limite, que ao ser virtualizado como reprodução fílmica para o DVD, segue rumo a um devir que o atualiza em relação ao seu produto original primeiro. A tecnologia torna-se também nova em relação àquela que a precedeu, no que, segundo Pierre Lèvy, as tecnologias de inteligência surgem como pretensão de serem novas de 
maneira unânime, absoluta. Isto em que seu sentido de realidade radical tende a romper com o já determinado, criando uma inovação que parte das imagens construídas ao redor dela (FELINTO, 2006:55).

Como no Limite, as novas tecnologias são infraestruturas altamente maleáveis e envolventes, porque elas abrem espaços ilimitados invisíveis que circulam fora das experiências humanas de espaço e tempo, desmaterializando-se, virtualizando-se. Como no filme de Mário Peixoto, o imaginário tecnológico fetichiza a máquina e converte a tecnologia de meio em uma finalidade absoluta (FELINTO, 2006:61). Do filme original e sua provável exclusão absoluta, o imaginário cede lugar ao desejo da substituição virtual, do racional pela imaginação. Um devir de superar as técnicas produzidas de uma época análoga ao novo, mas que rompendo com os estigmas passados, possa remetê-la para um novo contexto atualizado, como imaginário virtual.

\section{Considerações conclusiuas}

As mudanças apresentadas nos processos de realização audiovisual foram os assuntos destacados neste estudo. Questões que permeiam a evolução da imagem como técnica acontecem com o surgimento das máquinas fotográficas, datadas do século XIX, até o surgimento do movimento, proporcionado pela manipulação da fotografia. Deste modo, esta contribuição torna-se necessária para a entrada posterior do cinema e da televisão no século XX e das novas mídias digitais como a TV digital, final do século XX e início do século XXI.

Neste contexto, emerge novamente o conceito de aparelho de Flusser, onde entra toda a questão que envolve o hardware e o software como fonte inovativa da reprodução de imagens virtuais que estão em constante atualização. Tornam-se, com isso, conceitos de mundo, imagens dentro de imagens. Uma vez que remetem para uma não-presença. Nela, o real cede lugar para a imagem como conceito de mundo, falsa, enganosa.

A partir daí, imagens pré-históricas inserem-se no novo conteúdo da pós-história, com possibilidades de imagens técnicas como contribuições para uma teoria científica. Uma vez que as novas tecnologias digitais tendem a unir todos os sistemas de comunicação como sons, imagens, gestos, sentidos e etc. em sistemas híbridos e sincrônicos. Isto para que sirvam aos anseios de um produto que envolva todos estes fatores sensoriais que nos desterritorializam, jogando-nos para fora do ambiente histórico e não para dentro dele. 
Mesmo assim, no que tange ao fascínio, vale lembrar que as novas tecnologias de comunicação nos potencializam a uma grave crise latente que as coloca como manipuladoras de um caminho determinista sem volta. Neste sentido, é importante concluir que nossas vidas estão tornado-se extensões dos aparelhos virtuais. E que nos tornam ciborgues de um mundo codificado por sistemas matemáticos de linguagens textuais que participam do ciberespaço.

\section{Referências Bibliográficas}

FELINTO, Erick. Por uma crítica do imaginário tecnológico: novas tecnologias e imagens da transcendência. In:__ _ rebelião das máquinas, ensaios sobre o imaginário e cibercultura. Porto Alegre: Sulina, 2006. P. 53-70.

FLUSSER, Vilém. Códigos. In: $O$ mundo codificado: por uma filosofia do design e da comunicação. São Paulo: Cosac Naify, 2007.

LÉVY, Pierre. O que é o virtual. São Paulo: Ed 34, 1996.

PARENTE, André. O virtual e o hipertextual. Rio de Janeiro: Pazulin, 1999. P. 13-45.

PIGNATARI, Décio. Semiótica e literatura. $6^{a}$. Ed. São Paulo: Ateliê Editorial, 2004. P. 39-83.

STIEGLER, Bernard. La imagem discreta. In: DERRIDA, Jacques. Ecografias de la televisión. Entrevistas filmadas a Bernard Stiegler. Buenos Aires: Eudeba, 1998.

TEIXEIRA, Francisco E. O terceiro olho. São Paulo: Perspectiva, 2003. 